\title{
A Tradição Anglo-Saxônica nos Estudos Organizacionais Brasileiros
}

\author{
Suzana Braga Rodrigues \\ Alexandre de Pádua Carrieri
}

\section{RESUMO}

Este artigo analisa a evolução dos estudos organizacionais no Brasil, os temas eleitos como relevantes e a sua predominância no contexto da área de administração. Para tanto examinam-se os temas mais freqüentes nos periódicos da área e a importância relativa da literatura estrangeira nos artigos publicados. Neste sentido este trabalho tem por objetivo apenas apresentar um retrato do campo, sugerir pontos para reflexão dos seus atores e, portanto, servir de estímulo a investigações futuras mais aprofundadas.

Palavras-chaves: estudos organizacionais; gerência; tradição anglo-saxônica.

\begin{abstract}
This paper analyses the evolution of the organizational studies in Brazil, the themes elected as relevant and its predominance in the context of the administration area. For that, the most frequent themes are examined in the area's journals and the foreign literature's relative importance in the published papers. In this way this work has as a goal presenting a field's picture, suggesting points for its actors' reflection and, therefore, serving as an encouragement for deeper future investigations.
\end{abstract}

Key words: organizational studies; administration; anglo-saxon tradition. 


\section{INTRODUÇÃO}

A diversidade e a fragmentação nos estudos organizacionais têm levado a várias discussões e polêmicas sobre a identidade da área. Por exemplo, algumas discussões mais recentes levantaram algumas limitações importantes, que caracterizam as investigações neste campo (Chanlat, 1994; Whitley, 1995; Clegg e Hardy, 1996). Esses autores apontam não só as principais deficiências contextuais e históricas no processo de evolução dos estudos organizacionais como uma disciplina independente, mas também questionam a posição hegemônica desfrutada até então pelas teorias anglo-saxônicas e a adoção de modelos universais para explicar o que se passa no interior das organizações em outras regiões do mundo. Em 1977, Kenneth Benson já escrevia que a evolução dos estudos organizacionais deveria ser compreendida como processo de construção social e dialético, caracterizado por contradições e influenciado por grupos de interesses. Em 1985, Graham Astley também escreveu um artigo publicado pela Administrative Science Quarterly (ASQ), criticando o conhecimento organizacional como "uma coleção de tópicos frouxamente relacionados" (Astley, 1985, p. 504), culturalmente limitados ao contexto anglo-saxão e pouco ligados ao mundo da prática. Astley (1985) descreveu os estudos organizacionais como uma atividade social caracterizada por entendimento mútuo, dependente de consenso sobre o que se entende como sendo legítimas expressões de conhecimento. Nesse artigo, um tanto audacioso para a época como também para a própria ASQ, Astley (1985), ao revelar alguns dos critérios de inclusão e exclusão na hierarquia acadêmica e as condições para o acesso a periódicos de reputação, argumentou que os estudos organizacionais deveriam ser compreendidos como empreendimento socialmente construído. O autor chama a atenção para os gatekeepers, acadêmicos de renome, cujo papel consiste em definir o que é considerado um trabalho cientificamente relevante e, portanto, qual conhecimento deve ser entendido como legítimo.

Assim, a auto-reflexão e autocrítica neste campo não são novas; porém as mudanças que poderiam dar-lhe nova dimensão ou configuração não são muito profundas, mesmo considerando os novos paradigmas como a teoria crítica e a pósmodernista. Nos anos 80 , as críticas à área a acusavam de exagerado etnocentrismo, sem proporem sugestões que levassem a mudanças significativas. Mais recentemente, nos anos 90, autores como, por exemplo, Chanlat (1994) e Wilson (1996) chamaram a atenção para o etnocentrismo que caracterizava os estudos organizacionais até aquele momento, argumentando sobre a necessidade de se incorporar maior diversidade nas abordagens e de incluir novos colaboradores que pudessem trazer mudanças positivas no que se refere ao poder de explicação das suas teorias. 
Outra crítica muito comum refere-se ao uso de conceitos universalistas, cuja aplicação se supõe possa ser estendida a contextos industriais e culturais diversos (Hofstede, 1980, 1994); contudo a prática da pesquisa comparativa tem tornado evidentes as limitações das alternativas metodológicas e a dificuldade em captarem-se os significados comuns em ambientes não anglo-saxônicos. A maioria dos estudos comparativos em geral não revela as particularidades institucionais das sociedades investigadas, podendo apenas detectar parcialmente a natureza das organizações em sociedades diferentes. Os estudos comparativos sobre culturas e mesmo a teoria crítica não podem, isoladamente, cobrir as deficiências deixadas pelo exagerado etnocentrismo, as quais aparecem nos estudos organizacionais.

O Handbook de Estudos Organizacionais traz novo apelo, que é o de tratar os estudos organizacionais como conversações, como atividade social igual a qualquer outra, na qual as regras dependem do consenso sobre a identidade de determinado grupo. Sendo atividade socialmente construída e, portanto, sujeita ao alcance do consenso grupal, cabe a definição do campo como "um terreno contestável" (Reed, 1996). Trata-se de um lugar marcado por disputas teóricas, no qual o conhecimento se constrói na disputa sobre a verdade inerente a conceitos e esquemas referenciais. Assim, a identidade a ser assumida para o campo deveria ser não apenas flexível, mas incorporar a inovação como natural ou parte do processo de construção teórica. Ao adotarem a idéia de "conversações" como elementos definidores do campo, Clegg e Hardy (1996) sugerem que o conhecimento organizacional é produto da diversidade de locais, leitores e intérpretes, característica que lhe atribui uma identidade precária e constantemente sujeita a negociações. Esta idéia não apenas comporta a noção de que a teoria organizacional é um produto da cultura, senão que se trata também de um empreendimento, cujos produtos são freqüentemente negociados e submetidos a ajustes de significados. A idéia de um "terreno historicamente contestável" (Reed, 1996) sugere que o conhecimento organizacional está aberto a controvérsias e contestações, constantemente considerado objeto de refutação. Como "terreno historicamente contestável"(Reed, 1996), a teoria organizacional resultaria da competição de estruturas explicativas e de metodologias, cuja legitimidade estaria sujeita a critérios negociados via tradição e também histórica e contextualmente constituídos (Reed e Hughes, 1992). Ambos os artigos argumentam com a necessidade de incorporar maior diversidade, para que se possa gerar conhecimento relevante do ponto de vista da proximidade da realidade organizacional. Segundo Chanlat (1994), a crescente demanda por maior racionalismo econômico no mundo tem levado algumas escolas francesas a adotarem o modelo americano de educação gerencial, mas sem perderem a originalidade, e sem deixarem-se levar pelo paradigma funcionalista e pelos estudos quantitativos. O que chama a atenção nos artigos que mencionamos até o momento, que é de interesse para a 
América Latina e particularmente para o Brasil, não é tanto o caráter etnocêntrico do conhecimento organizacional por si só; porquanto isto já é muito bem conhecido e amplamente criticado aqui. O que parece relevante para nós, neste debate, é o reconhecimento da necessidade de haver maior sensibilidade com relação às estruturas organizacionais em economias emergentes (Calás, 1994), e a necessidade de incluir-se vozes diversas que não pertencem aos limites geográficos e lingüísticos dominantes (Chanlat, 1994; Whitley, 1995; Clegg e Hardy, 1996).

Tendo por base a argumentação de Clegg e Hardy (1996) de que os estudos organizacionais se desenvolvem por meio de conversações, este artigo procura analisar a evolução dos estudos organizacionais no Brasil, quais temas têm sido eleitos como relevantes e qual a sua predominância no contexto da área de administração. Para tanto examinam-se quais são os temas mais freqüentes nos periódicos da área e a importância relativa da literatura estrangeira, nos artigos publicados. Neste sentido o artigo tem por objetivo apenas apresentar um retrato do campo, sugerir pontos para a reflexão dos seus atores e, assim, servir de estímulo a investigações futuras mais aprofundadas.

\section{A Importância de Revisar a Disciplina no Brasil}

O uso do termo conversações para identificar o processo de construção social do campo dos estudos organizacionais induz idéias de troca, participação, pluralismo e, portanto, carrega um significado de inclusão. Admite a interpretação de que a inclusão de novas perspectivas e participantes pode resultar num melhor entendimento acerca das organizações e suas particularidades locais. De fato, esta perspectiva adquire importância crítica, tanto para aqueles excluídos como também para aqueles que estão insertos no centro do debate. Para os excluídos ela pode representar uma possibilidade de inclusão no grupo central ou no main stream; já para os incluídos no centro do debate, ela pode ser vista como oportunidade para o fortalecimento das idéias e metodologias defendidas pelo main stream em condições em que pairam ameaças à integridade do campo. Por exemplo, alguns vêem as pressões para maior colaboração com o setor empresarial como um fator de interferência na sua autonomia.

No Brasil, os estudos organizacionais iniciaram-se há vinte anos. Atualmente já existe um corpo de conhecimento expressivo neste campo. Grande parte da literatura que hoje apóia esses estudos é de origem americana e britânica. A influência exercida pelos estudos organizacionais nas escolas e departamentos de administração de empresas tem sido expressiva desde a criação dos cursos de 
graduação; em particular, desde a criação da pós-graduação no país. Recentemente, no entanto, a abertura dos mercados e a competitividade internacional trouxeram pressões para maior qualificação em outras áreas gerenciais, tais como planejamento, estratégia, finanças, marketing e informações. Essas pressões muito contribuíram para tornar relativa a importância dos estudos organizacionais nas instituições de ensino e pesquisa, com conseqüência para a produção acadêmica na área de administração que, em vez de concentrar-se predominantemente no campo organizacional, é hoje divida entre outras áreas temáticas.

Nas décadas de 70 e 80 , os especialistas de estudos organizacionais foram muito influentes na constituição da administração como área acadêmica e de pesquisa, pois foram os primeiros a ocupar posições de tempo integral nas universidades, onde havia escassez de profissionais com alta qualificação acadêmica nas subáreas de marketing e finanças. Durante esses anos de escassez de profissionais qualificados, muitos dos iniciantes com doutorado eram rapidamente absorvidos pelo mercado. Assim, restou ao campo dos estudos organizacionais a missão de definir os critérios de qualificação gerencial, que passaram a ser pautados pelo treinamento em pesquisa somente adquirido pela pós-graduação stricto sensu.

Os programas de pós-graduação em administração nas universidades públicas tiveram, e ainda têm, um papel muito importante na legitimação do conhecimento básico em pesquisa, como o critério mais importante para a certificação em administração. A estrutura americana de estudos gerenciais teve muita influência no processo de institucionalização desse modelo. A importância do pensamento americano ainda pode ser observada no conteúdo curricular dos programas de graduação e pós-graduação, que dividiram a administração em compartimentos como finanças, gerenciamento de produção, marketing e estudos organizacionais. Embora no período de sua criação muitos programas de mestrado não oferecessem finanças e marketing, quase todos possuíam especialização em estudos organizacionais.

A influência norte-americana iniciou-se nos anos $50 \mathrm{com}$ a primeira onda de inserção de capital estrangeiro para o Brasil. Foi a instalação de multinacionais norte-americanas e européias no Brasil que trouxe a motivação e a necessidade de melhorar as habilidades gerenciais. Durante esse período e principalmente no início dos anos 60, as multinacionais, empresas estrangeiras de consultoria e o governo pressionaram a criação de escolas de administração, que se dedicassem prioritariamente a formação de uma mentalidade burocrática dentro do setor público. Mais tarde, nos anos 70, o governo militar também encorajou o estabelecimento de programas de pós-graduação em administração de empresas, visando a desenvolver habilidades que pudessem ajudar empresas privadas e estatais a introduzirem alguma racionalidade dentro de suas estruturas de decisão e com 
isso melhorar o seu desempenho. Nesta data predominavam, portanto, os estudos sobre a burocracia, sobre a racionalidade decisória e sobre as pressões ambientais na estruturação organizacional.

Além disso, os primeiros programas de pós-graduação criados no Brasil nos anos 70, como os da Universidade Federal de Minas Gerais (UFMG), da Universidade Federal do Rio Grande do Sul (UFRGS) e da Fundação Getúlio Vargas (FGV) de São Paulo, tiveram o apoio de professores das escolas americanas de administração na constituição de seus currículos, assim como muitos desses professores ensinaram regularmente nesses mesmos programas de mestrado por pelo menos dois anos após o período de criação.

Assim, a influência do pensamento anglo-saxônico deu-se não somente por influxo das multinacionais que passaram a atuar no Brasil, mas também pela influência dos scholars americanos que contribuíram na fundação dos programas gerenciais. Se de um lado a presença dos especialistas em teoria organizacional nas escolas de gerência foi importante para que o campo tivesse uma posição privilegiada entre as demais disciplinas, não se pode negligenciar a influência das multinacionais, em particular dos americanos, na transmissão da tradição anglo-saxônica nestas mesmas escolas. Apesar do seu início brilhante no Brasil, recentemente a influência dos estudos organizacionais parece estar em declínio, conforme se discute no decorrer deste artigo. Nele procuramos levantar algumas hipóteses que podem explicar este declínio, entre elas as pressões para que as instituições de pesquisa e a produção de conhecimento apresentem soluções que possam contribuir de maneira imediata para o progresso econômico, condição a que a maioria dos estudos organizacionais ainda não tem condições de responder. Outro fator refere-se ao aumento do poder das áreas de conhecimento tecnológico e prático, em detrimento da geração de conhecimento mais abstrato e sem aplicação imediata ou de longo prazo. Esta reflexão deverá ser retomada mais adiante neste artigo. Primeiramente é necessário discutir a evolução da área e apresentar informações sobre o que se investiga hoje no campo.

\section{Estudos Anteriores}

Uma investigação conduzida por Machado-da-Silva, Cunha e Amboni (1990) mostrou que os tópicos mais freqüentemente discutidos de 1985 a 1989 nos quatro periódicos mais importantes eram também aqueles encontrados em qualquer periódico americano, tais como mudança e inovação, administração e planejamento, tomada de decisão, desempenho organizacional, ambiente e relações organizacionais, poder e conflito, cultura e clima organizacionais, centralização 
e descentralização, burocracia e tecnocracia. De acordo com esse estudo, grande parte desses artigos preocupa-se com mudança e inovação organizacional (23\%), e administração e planejamento (27\%). O fato de esses temas serem os mais populares, segundo os autores, pode estar ligado aos problemas que o Brasil estava enfrentando em meados dos anos 80 . Durante esse período, os principais problemas gerenciais concentravam em como fazer as empresas sobreviverem na instabilidade econômica que afligia o país. As mudanças repentinas nas políticas governamentais e as constantes modificações nas normas e regulações dos negócios privados impunham pressões, que reforçavam o imediatismo. Enquanto para a empresa privada a questão de sobrevivência era parcial e temporariamente solucionada pelos seus laços estreitos com o governo e respectivas políticas de proteção, o principal problema com serviços públicos era sua endêmica ineficiência, que levou posteriormente à política de privatização. A despeito de o planejamento ser um tópico central e tradicional no discurso da administração, até o Plano Real havia poucos indícios dessa prática nas empresas brasileiras.

Já o estudo conduzido por Bertero e Keinert (1994) focaliza a trajetória dos estudos organizacionais no Brasil de 1961 a 1993. Esse trabalho conclui que o conhecimento produzido no contexto brasileiro foi uma grande e fiel reprodução do pensamento americano. Na análise de 184 artigos publicados nesse período, descobriu-se que a maioria das variáveis neles investigadas, eram as mais freqüentemente encontradas nos periódicos americanos. De acordo com a classificação paradigmática de Güillén (1994), as teorias discutidas nos artigos brasileiros eram aquelas de caráter genérico e com maior alcance internacional: administração científica, relações humanas (incluindo as perspectivas comportamentais e psicológicas) e análises estruturais. O estudo de Bertero e Keinert (1994) sugere que um grupo de artigos mais recentes incluia uma variedade de outras perspectivas, tais como estudos sobre burocracias, teorias de sistemas, administração por objetivos, gerenciamento participativo, mudança e estratégia organizacional. Na interpretação dos autores, uma parte dos trabalhos brasileiros reproduzia os sistemas americanos; outros artigos optaram pela refutação desse modelo, evidenciando suas limitações, na tentativa de explicar as organizações brasileiras; entretanto $17 \%$ da amostra era, fundamentalmente, de origem reflexiva ou crítica, não conseguindo avançar ou acrescentar novas idéias às teorias estrangeiras existentes. Os autores concluíram que havia necessidade de se criarem perspectivas mais apropriadas ao contexto brasileiro.

Uma revisão mais recente foi feita por Vergara e Carvalho (1995). Tomando como amostra os artigos publicados nos anais dos Encontros Anuais da Associação Nacional dos Programas de Pós-Graduação em Administração (ENANPAD) de 1989 a 1993, os autores analisaram as principais fontes de referências teóricas que apoiavam esses artigos. Esse estudo apontou que os 
autores brasileiros basearam-se mais na literatura estrangeira, mais precisamente na combinação de citações americanas e britânicas. Ao investigar as razões de tais preferências, concluiu-se que a predominância da literatura estrangeira estava mais ligada à necessidade de referir-se a um conhecimento já legitimado no circuito internacional do que a sua capacidade de explicar os problemas investigados. Não que se julgasse a literatura nacional inferior em qualidade, mas a explicação mais plausível para a predominância da literatura estrangeira poderia ser atribuída a sua falta de prestígio e alcance internacional.

\section{O Estágio Atual da Disciplina no Brasil}

Conforme mencionamos anteriormente, as pesquisas realizadas sobre os estudos organizacionais no Brasil sugerem que a área se tem desenvolvido, mas não tanto quanto seria esperado, principalmente levando-se em conta o aumento de pessoal com alta qualificação e a crescente institucionalização das atividades acadêmicas nas duas últimas décadas. Uma das razões pode ser o pequeno número de instituições, cujo objetivo é prestar apoio às atividades acadêmicas. Ainda não se criou um periódico específico em estudos organizacionais a despeito do fato de a maioria das publicações em periódicos de administração brasileira tratar de organizações. As Tabelas 1, 2, 3 e 4 ilustram os cinco principais tópicos que são freqüentemente discutidos pelos quatro principais periódicos acadêmicos na área: Revista de Administração Contemporânea (RAC), ligada à ANPAD; Revista de Administração de Empresas (RAE), ligada à Fundação Getúlio Vargas de São Paulo; Revista de Administração Pública (RAP), ligada à Escola de Administração Pública no Rio de Janeiro e a Revista de Administração (RAUSP), ligada à Faculdade de Economia, Administração e Contabilidade da Universidade de São Paulo.

\section{Tabela 1: Cinco Principais Temas Publicados pela RAC - Revista de Administração Contemporânea (1997-1999)}

\begin{tabular}{|l|c|c|c|c|}
\hline Temas & $\mathbf{1 9 9 7}$ & $\mathbf{1 9 9 8}$ & $\mathbf{1 9 9 9}$ & Total \\
\hline Estudos Organizacionais & $\mathbf{6}$ & $\mathbf{7}$ & $\mathbf{5}$ & $\mathbf{1 8}$ \\
\hline Administração de Recursos Humanos & 3 & 3 & 1 & 7 \\
\hline Sistemas de Informação & 3 & - & 4 & 7 \\
\hline Finanças & 2 & 3 & 1 & 6 \\
\hline Planejamento e Gerenciamento de Produção & - & 3 & 3 & 6 \\
\hline Total & 14 & 16 & 14 & 44 \\
\hline
\end{tabular}


Tabela 2: Cinco Principais Temas Publicados pela RAE - Revista de Administração de Empresas (1994-1999)

\begin{tabular}{|l|c|c|c|c|c|c|c|}
\hline Te mas & $\mathbf{1 9 9 4}$ & $\mathbf{1 9 9 5}$ & $\mathbf{1 9 9 6}$ & $\mathbf{1 9 9 7}$ & $\mathbf{1 9 9 8}$ & $\mathbf{1 9 9 9}$ & Total \\
\hline Estudos Organizacionais & $\mathbf{1 9}$ & $\mathbf{1 1}$ & $\mathbf{3}$ & $\mathbf{6}$ & $\mathbf{6}$ & $\mathbf{6}$ & $\mathbf{5 1}$ \\
\hline Finanças & 3 & 3 & 3 & 3 & 3 & 4 & 19 \\
\hline $\begin{array}{l}\text { Marketing } \\
\text { Planejamento e }\end{array}$ & 4 & 5 & 4 & 3 & 1 & 2 & 19 \\
$\begin{array}{l}\text { Gerenciamento de } \\
\text { Produção }\end{array}$ & 5 & 2 & 1 & 3 & 3 & 3 & 17 \\
\hline $\begin{array}{l}\text { Planejamento Estratégico } \\
\text { Total }\end{array}$ & 2 & 4 & 2 & 3 & - & 3 & 14 \\
\hline
\end{tabular}

Tabela 3: Cinco Principais Temas Publicados pela RAP - Revista de Administração Pública (1994-1999)

\begin{tabular}{|l|c|c|c|c|c|c|c|}
\hline Temas $\backslash$ Anos & $\mathbf{1 9 9 4}$ & $\mathbf{1 9 9 5}$ & $\mathbf{1 9 9 6}$ & $\mathbf{1 9 9 7}$ & $\mathbf{1 9 9 8}$ & $\mathbf{1 9 9 9}$ & Total \\
\hline Estudos Organizacionais & $\mathbf{4}$ & $\mathbf{1 1}$ & $\mathbf{8}$ & $\mathbf{4}$ & $\mathbf{6}$ & $\mathbf{6}$ & $\mathbf{3 9}$ \\
\hline Política Governamentais & 2 & 14 & 6 & 6 & 5 & 4 & 37 \\
\hline $\begin{array}{l}\text { Gestão de Saúde / } \\
\text { Sistemas de Saúde }\end{array}$ & 4 & 3 & 4 & 5 & 10 & 5 & 31 \\
\hline $\begin{array}{l}\text { Reforma de Estado / } \\
\text { Modernização }\end{array}$ & 7 & 2 & 4 & 4 & 4 & 2 & 23 \\
\hline $\begin{array}{l}\text { Administração de Recursos } \\
\text { Humanos }\end{array}$ & 2 & 1 & 1 & 1 & 6 & 2 & 13 \\
\hline Total & 19 & 31 & 23 & 20 & 31 & 19 & 143 \\
\hline
\end{tabular}

Tabela 4: Cinco Principais Temas Publicados pela RAUSP - Revista de Administração da USP (1994-1999)

\begin{tabular}{|l|c|c|c|c|c|c|c|}
\hline Te mas & $\mathbf{1 9 9 4}$ & $\mathbf{1 9 9 5}$ & $\mathbf{1 9 9 6}$ & $\mathbf{1 9 9 7}$ & $\mathbf{1 9 9 8}$ & $\mathbf{1 9 9 9}$ & Total \\
\hline Estudos Organizacionais & $\mathbf{2}$ & $\mathbf{5}$ & $\mathbf{3}$ & $\mathbf{5}$ & $\mathbf{4}$ & $\mathbf{3}$ & $\mathbf{2 2}$ \\
\hline Finanças & 3 & 1 & 4 & 3 & 3 & 1 & 15 \\
\hline Ciência e Tecnologia & - & 3 & 2 & 2 & 3 & 3 & 13 \\
\hline $\begin{array}{l}\text { Administração de Recursos } \\
\text { Humanos }\end{array}$ & 1 & 1 & 2 & 4 & 3 & 1 & 12 \\
\hline Informação Tecnológica & 1 & 1 & 3 & 2 & 1 & 3 & 11 \\
\hline Total & 7 & 11 & 14 & 16 & 14 & 11 & 73 \\
\hline
\end{tabular}


A Tabela 5 apresenta o número de artigos examinados em cada periódico. Foram analisados os artigos publicados entre 1994 e 1999, com exceção dos volumes referentes a 1999 da RAP. As publicações da RAC foram analisadas a partir de 1997, data da criação do periódico.

Tabela 5: Número de Artigos Examinados por Periódico

\begin{tabular}{l|rrrrrrr}
\hline Periódicos $\backslash$ Anos & $\mathbf{1 9 9 4}$ & $\mathbf{1 9 9 5}$ & $\mathbf{1 9 9 6}$ & $\mathbf{1 9 9 7}$ & $\mathbf{1 9 9 8}$ & $\mathbf{1 9 9 9}$ & Total \\
\hline RAC - Artigos (fascículos) & - & - & - & $19(3)$ & $23(3)$ & $22(3)$ & 64 \\
RAE - Artigos (fascículos) & $56(6)$ & $51(6)$ & $25(4)$ & $27(4)$ & $28(4)$ & $29(4)$ & 216 \\
RAP - Artigos (fascículos) & $45(4)$ & $52(4)$ & $46(6)$ & $47(6)$ & $56(6)$ & $36(5)$ & 282 \\
RAUSP - Artigos (fascículos) & $22(4)$ & $24(4)$ & $28(4)$ & $30(4)$ & $28(4)$ & $27(4)$ & 159 \\
$N^{o}$ Total de artigos & 123 & 127 & 99 & 123 & 135 & 114 & 721 \\
\hline
\end{tabular}

É importante mencionar que a classificação dos artigos aqui apresentada foi feita pelos autores deste artigo, não havendo coincidência com a classificação do próprio periódico. A RAE, por exemplo, utiliza classificações múltiplas, podendo o mesmo artigo ser classificado como estratégia ou como pertinente a estudos organizacionais ao mesmo tempo. Para o propósito deste trabalho, cada artigo foi classificado em apenas uma categoria, havendo correspondência entre o número de tópicos e o número de artigos publicados pelo periódico durante o período examinado. Somente as edições regulares foram examinadas. Notas, discussões e revisões de livros foram excluídas desta investigação. A separação entre os tópicos de estudo organizacional e os demais teve por base não apenas o que é usualmente definido como main stream, mas também procurou-se verificar se a perspectiva utilizada no estudo é organizacional ou gerencial; portanto a categoria de estudos organizacionais nas Tabelas 1, 2, 3 e 4 inclue as perspectivas teóricas convencionais, comportamento simbólico e cultura organizacional e perspectivas estruturais de organizações. Tópicos como informação tecnológica, internacionalização e sistemas de cooperação foram mantidos fora do âmbito dos estudos organizacionais, devido a uma maior ênfase em soluções gerenciais do que em entendimento de processos (vide Tabelas 1, 2, 3, 4 e 6).

Neste artigo, os tópicos considerados fora do âmbito dos estudos organizacionais em publicações da RAP, RAE e RAUSP aparecem de outra maneira, quando se examinam os anais do ENANPAD. Por exemplo, o tópico vantagem competitiva não foi incluido na categoria estudos organizacionais na análise dos periódicos, embora seja visto como assunto importante nos anais do ENANPAD. Este tópico foi contado como pertencente à categoria somente quando a perspectiva de análise era a organizacional. Nos anais do ENANPAD, a seleção do que era considerado como pertencente ao campo já havia sido feita previa- 
mente pelos respectivos coordenadores de tema da reunião. O mesmo se aplica ao controle de qualidade total; portanto as categorias encontradas na Tabela 6 refletem parcialmente o processo de revisão por coordenadores da área de organizações do ENANPAD. Os artigos dos anais foram então divididos em subtópicos de acordo com o seu título e perspectivas adotadas. Enquanto neste artigo a intenção era identificar os tópicos que os pesquisadores acharam importantes nos últimos anos e também a relevância dos estudos organizacionais no contexto da educação gerencial.

\section{Tabela 6: Os Quinze Temas Mais Freqüentemente Abordados por Autores Brasileiros nos Anais do ENANPAD}

\begin{tabular}{|c|c|c|c|c|c|c|c|c|c|c|c|}
\hline Te mas \Anos & 1990 & 1991 & 1992 & 1993 & 1994 & 1995 & 1996 & 1997 & 1998 & 1999 & Total \\
\hline Epistemologia & 6 & 7 & 8 & 8 & - & 3 & 8 & 6 & 7 & 7 & 60 \\
\hline $\begin{array}{l}\text { Cultura } \\
\text { Organizacional }\end{array}$ & 4 & 3 & 2 & 5 & 5 & 3 & 11 & 8 & 5 & 5 & 51 \\
\hline $\begin{array}{l}\text { Mudança e Inovação } \\
\text { Organizacional }\end{array}$ & 2 & 2 & 3 & 2 & 3 & 3 & 5 & 5 & 5 & 7 & 37 \\
\hline $\begin{array}{l}\text { Estrutura } \\
\text { Organizacional }\end{array}$ & 2 & 3 & 1 & - & 4 & - & 2 & - & 3 & 1 & 16 \\
\hline \begin{tabular}{|l|} 
Processos \\
Decisórios \\
\end{tabular} & - & 3 & 5 & - & 1 & 2 & 1 & - & 2 & 2 & 16 \\
\hline $\begin{array}{l}\text { Comprometimento } \\
\text { Organizacional }\end{array}$ & - & 1 & - & 1 & - & 1 & - & 2 & 3 & 5 & 13 \\
\hline \begin{tabular}{|l} 
Controle de \\
Qualidade Total \\
\end{tabular} & - & 1 & - & 2 & 1 & 1 & 1 & 2 & 3 & 2 & 13 \\
\hline $\begin{array}{l}\text { Aprendizagem e } \\
\text { Conhecimento } \\
\text { Organizacional }\end{array}$ & - & - & - & - & - & 1 & 2 & 2 & 2 & 6 & 13 \\
\hline $\begin{array}{l}\text { Estratégia } \\
\text { Organizacional }\end{array}$ & 3 & 1 & 3 & - & & 2 & - & $* 1$ & $*$ & $*$ & 9 \\
\hline Poder & - & - & 1 & 1 & - & 1 & 1 & 2 & 1 & 2 & 9 \\
\hline $\begin{array}{l}\text { Vantagem } \\
\text { Competitiva }\end{array}$ & - & - & - & 2 & 1 & 2 & - & 1 & 1 & - & 7 \\
\hline $\begin{array}{l}\text { Desempenho } \\
\text { Organizacional }\end{array}$ & 2 & - & - & - & 1 & - & - & 1 & 1 & 1 & 6 \\
\hline Qualidade de Vida & 1 & - & - & - & - & - & - & 1 & 1 & 2 & 5 \\
\hline $\begin{array}{l}\text { Stress nas } \\
\text { Organizações }\end{array}$ & - & 1 & - & - & - & - & 1 & 1 & 1 & 1 & 5 \\
\hline $\begin{array}{l}\text { Ecologia nas } \\
\text { Organizações }\end{array}$ & 1 & - & 1 & - & 3 & - & - & - & - & - & 5 \\
\hline Total & 21 & 22 & 24 & 21 & 19 & 19 & 32 & 31 & 35 & 41 & 265 \\
\hline
\end{tabular}

${ }^{1}$ No ano de 1997 foi criada a área temática de Organização/Estratégia. 
A RAC é uma revista nova, comparada com os outros periódicos analisados. A área de estudos organizacionais tem tido certa relevância nesse periódico como se pode observar na Tabela 1 ; todavia, em sendo uma revista ligada à ANPAD, cobre temas que se destacaram nas diversas áreas de conhecimento dos respectivos encontros nacionais promovidos pela entidade.

A RAE, que tem sido por muitos anos considerada um periódico de natureza mais acadêmica, tem agora adotado o caminho de uma abordagem mais pragmática (Bertero e Keinert, 1994), focalizando as áreas de administração mais tradicionais, como marketing, finanças, gerenciamento de produção, administração de sistemas de informação e planejamento estratégico (vide Tabela 2). A maioria de seus artigos são discutidos a partir de uma perspectiva prática, mesmo quando envolvem um tópico teórico, como cultura e ética organizacional.

Já a RAP concentra-se predominantemente em artigos sobre política e administração pública, dando ênfase à educação, saúde, reforma e modernização do Estado e também aos estudos governamentais (vide Tabela 3).

O periódico RAUSP parece o mais acadêmico dos três periódicos mais antigos analisados e o mais regular em termos de números de assuntos publicados (vide Tabela 4). Embora os artigos aí publicados sejam também orientados para tópicos práticos, há uma preocupação com as implicações teóricas e conseqüências mais amplas do problema discutido. Em outras palavras, existe menos diversidade nos assuntos discutidos nesse periódico em comparação com a RAP e a RAE. Além dos tópicos de organização, a maioria de seus artigos concentra-se em finanças, em ciência e tecnologia, na administração de recursos humanos, em informação tecnológica, em alianças estratégicas e na administração de qualidade total (vide Tabela 4).

Os estudos organizacionais tradicionalmente têm predominado em todos os quatro periódicos, conforme os dados nas tabelas mencionadas acima; entretanto, em 1996, houve um declínio no número de artigos publicados em praticamente todos os periódicos. É importante mencionar que a RAE havia publicado aproximadamente metade dos artigos nos dois anos anteriores. A RAP também apresentou redução no número total de artigos publicados no último ano. O declínio no número de publicações sobre estudos organizacionais em 1996 pode refletir uma diminuição no número total de artigos submetidos a esses periódicos ou então sinalar uma tendência de redução. Alternativamente, poder-se-ia argumentar que os temas discutidos resultam de uma política particular do periódico de conceder maior primazia às demandas de outros leitores, em vez de priorizar os da academia (Bertero e Keinert, 1994). Conforme Astley (1985) assinalou, os interesses dos leitores podem ser os mais diversos e distantes um do outro; mas, quando alguém procura adaptar-se às demandas do mercado, estas podem estar ligadas a modismos, mais do que representar inovações no campo. 
Nos anos seguintes, 1997, 1998 e 1999, os estudos organizacionais não conseguem atingir os patamares anteriores a 1996. Tanto a RAE como a RAP parecem estar caminhando para um número mais constante ou regular sobre esse tema, similarmente ao que vem acontecendo com os periódicos RAC e RAUSP.

Os dados apresentados até o momento sugerem que o principal fórum para debates em estudos organizacionais continuam a ser os Encontros Anuais da ANPAD. Para ter melhor idéia do campo, além de investigar o conteúdo dos quatro principais periódicos na área, RAC, RAE, RAP e RAUSP, ao longo dos sete últimos anos, examinaram-se também as sessões de Organização dos anais do ENANPAD de 1990 à 1999. Como pode ser observado na Tabela 6, a mudança e a inovação organizacional continuam a ser um tópico importante para os autores brasileiros, conforme haviam apontado anteriormente Machado-da-Silva, Cunha e Amboni (1990). O tema mudança e inovações foi o terceiro com maior número de artigos encontrado na análise. $\mathrm{O}$ tema cultura organizacional tem sido também um dos tópicos preferidos. Evidencia-se o ano de 1996 como um ano no qual o tema foi referência para 11 artigos. Cultura organizacional é o segundo tema em número de artigos. Em seu estudo, Bertero e Keinert (1994) notam o grande interesse dos autores brasileiros em escrever acerca da construção do campo. Isto também é evidenciado nos anais do ENANPAD, onde os estudos em epistemologia constituem o primeiro tema em número de artigos. Nos últimos anos, novos temas ganharam relevância, tais como aprendizagem, conhecimento organizacional e comprometimento organizacional.

Assim como os franceses (Chanlat, 1994), os brasileiros também preferem as metodologias qualitativas (vide Tabela 7); todavia, a partir do ano de 1996, a metodologia quantitativa começa a tornar-se mais comum nos trabalhos analisados. É também a partir desse ano que os estudos de caso ultrapassam os artigos eminentemente teóricos, o que condiz com o aumento da perspectiva mais pragmática. De certo modo, observa-se a preocupação de vários trabalhos em discutir os problemas vivenciados pelas empresas, por seus gerentes, enfim pelas pessoas que nelas estão insertas.

Ainda neste estudo, examinamos 292 artigos das sessões de Organização, do ENANPAD. Com relação à freqüência de citações dos autores listados na obra Writers on Organizations de Pugh e Hickson (1997), a Tabela 8 mostra a freqüência de citação desses autores de 1990 até 1999. Essa tabela apresenta o número de citações mais freqüentemente referenciadas por brasileiros. Indiretamente, os resultados também sugerem a extensão na qual os autores confiam nos modelos anglo-saxônicos. O procedimento adotado consistiu em registar a frequência na qual cada trabalho de determinado autor constava como referência em cada artigo. 
Tabela 7: Metodologia e Perspectivas Mais Freqüentes Adotadas em Artigos Publicados nos Anais do ENANPAD

\begin{tabular}{|c|c|c|c|c|c|}
\hline Metodologia & \multicolumn{3}{|c|}{ Método } & \multicolumn{2}{c|}{ Perspectiva Adotada } \\
\hline Ano & Quantitativo & Teórico & $\begin{array}{c}\text { Estudo de } \\
\text { Caso }\end{array}$ & $\begin{array}{c}\text { Crítica ou } \\
\text { Reflexiva }\end{array}$ & Prática \\
\hline $\mathbf{1 9 9 0}$ & 4 & 12 & 5 & 12 & 9 \\
\hline $\mathbf{1 9 9 1}$ & 4 & 10 & 11 & 10 & 15 \\
\hline $\mathbf{1 9 9 2}$ & 1 & 11 & 12 & 11 & 13 \\
\hline $\mathbf{1 9 9 3}$ & - & 16 & 8 & 16 & 8 \\
\hline $\mathbf{1 9 9 4}$ & - & 12 & 9 & 12 & 9 \\
\hline $\mathbf{1 9 9 5}$ & 4 & 9 & 9 & 9 & 13 \\
\hline $\mathbf{1 9 9 6}$ & - & 12 & 19 & 12 & 19 \\
\hline $\mathbf{1 9 9 7}$ & 4 & 11 & 15 & 11 & 22 \\
\hline $\mathbf{1 9 9 8}$ & 6 & 14 & 23 & 14 & 26 \\
\hline $\mathbf{1 9 9 9}$ & 9 & 17 & 25 & 17 & 34 \\
\hline Total & 32 & 124 & 136 & 124 & 168 \\
\hline
\end{tabular}

Entre os autores modernos, Gareth Morgan é o mais bem citado com seu livro Images of Organization e o livro de Gibson Burrell, Sociological Paradigms and Organization Analysis. O próximo na lista é Edgar Schein com o livro Organizational Culture and Leadership e Max Weber com Ensaios de Sociologia, Economia e Sociedade e A Ética Protestante e o Espírito do Capitalismo. Logo após aparece Henry Mintzberg, principalmente com seu livro The Structuring of Organizations. Em seguida vem Geert Hofstede com sua obra Culture's Consequences: International Differences in Work-Related Values e o artigo publicado na Administrative Science Quarterly, Measuring Organizational Cultures: a Qualitative and Quantitative Study Across Twenty Cases. Em seguida vem o artigo de Andrew Pettigrew do Journal of Management Studies, Context and Action in the Transformation of the Firm e o único publicado pela Organizational Science, Longitudinal Field Research on Change. É importante notar que, de 1991 até 1995, o número de citações de autores na lista de Pugh e Hickson (1997) se mantinha aproximadamente na mesma média. Destaca-se que em 1996, as referências voltam ao patamar de 1990; mas, em 1999, a soma das referências aos autores de Writers on Organizations atinge o patamar de 109, quase que dobrando seu número em 10 anos. Autores considerados clássicos como Taylor, Fayol, Braverman, Simon, entre outros são também muito citados. 
Tabela 8: Autores Mais Freqüentemente Citados nos Anais do ENANPAD Mas Não Incluídos no Writers on Organizations

\begin{tabular}{|l|c|c|c|c|c|c|c|c|c|c|c|}
\hline Autores $\backslash$ Anos & $\mathbf{1 9 9 0}$ & $\mathbf{1 9 9 1}$ & $\mathbf{1 9 9 2}$ & $\mathbf{1 9 9 3}$ & $\mathbf{1 9 9 4}$ & $\mathbf{1 9 9 5}$ & $\mathbf{1 9 9 6}$ & $\mathbf{1 9 9 7}$ & $\mathbf{1 9 9 8}$ & $\mathbf{1 9 9 9}$ & Total \\
\hline Clegg & 8 & 6 & 2 & 3 & 2 & 3 & 4 & 4 & 9 & 9 & 50 \\
\hline $\begin{array}{l}\text { Berger/ } \\
\text { Luckmann }\end{array}$ & 2 & - & - & 4 & 2 & 1 & 4 & 3 & 3 & 7 & 26 \\
\hline Chanlat & - & 1 & 4 & 2 & 1 & 2 & 3 & 4 & 5 & 5 & 26 \\
\hline Blau & 4 & 8 & 3 & - & 1 & 1 & 2 & 3 & 1 & 2 & 25 \\
\hline Aktouf & 1 & 1 & 3 & 1 & 4 & - & 3 & 3 & 3 & 4 & 23 \\
\hline Etzioni & - & 3 & 4 & - & 1 & 2 & 2 & 3 & 6 & 2 & 23 \\
\hline Bourdieu & 6 & - & 1 & - & - & - & 4 & 3 & 2 & 4 & 20 \\
\hline Habermas & - & 1 & 6 & 2 & 1 & 1 & - & 2 & 4 & 3 & 20 \\
\hline Perrow & 1 & 2 & 3 & 3 & - & 1 & 1 & 3 & 4 & 2 & 20 \\
\hline Pagès & 1 & 3 & 2 & 1 & 1 & 1 & 1 & 4 & 2 & 3 & 19 \\
\hline Ansoff & - & 1 & 4 & - & 1 & - & 4 & 1 & 1 & 1 & 13 \\
\hline Drucker & - & - & - & - & - & - & - & 3 & 4 & 4 & 11 \\
\hline
\end{tabular}

A Tabela 8 inclui citações de outros autores que não estão na lista do Writers on Organizations, mas freqüentemente são citados em artigos brasileiros. Esta tabela inclui somente aqueles que obtiveram mais de 10 citações nas sessões de Organização dos anais do ENANPAD analisados, enquanto a Tabela 9 inclui os autores na lista de Pugh e Hickson (1997) e o número de vezes em que cada referência é citada. Esta tabela mostra que o trabalho de Clegg é bem conhecido no Brasil, em particular os livros Frameworks of Power e Modern Organizations. Os sociólogos americanos tais como Blau, Etzioni e Perrow são muito referenciados como apoio em estudos de estrutura organizacional, burocracia, organizações e ambiente. O livro de Berger e Luckmman The Social Construction of Reality tem sido usado fundamentalmente nos artigos relacionados à cultura organizacional, mas principalmente nos estudos epistemológicos.

A literatura francesa tem sido muito influente em ciências sociais no Brasil, assim como a teoria crítica social alemã por meio da obra de Habermas (vide Tabela 8). Os estudos de Crozier sobre burocracias e poder (vide Tabela 9) são bem conhecidos e referenciados; notavelmente também a teoria de Bourdieu sobre o capital simbólico e hábitos, além de autores marxistas tais como Althusser e Polantzas. A literatura francesa tem exercido influência em várias áreas de conhecimento no Brasil; alguns estudos têm sido particularmente importantes não somente na área de organizações como também em recursos humanos, em 
particular nas áreas sobre processo e relações de trabalho, como aqueles de Chanlat e Aktouf, para mencionar apenas alguns. Destaca-se uma forte influência de Chanlat e seu livro O Indivíduo na Organização: Dimensões Esquecidas.

Tabela 9: Autores Listados no Writes on Organization. Número de Autores Citados pelo Menos Uma Vez nos Artigos, Sessão Organização, dos Anais do ENANPAD

\begin{tabular}{|c|c|c|c|c|c|c|c|c|c|c|c|}
\hline Autore $\backslash \backslash$ Anos & 1990 & 1991 & 1992 & 1993 & 1994 & 1995 & 1996 & 1997 & 1998 & 1999 & Total \\
\hline Total & 57 & 38 & 29 & 21 & 28 & 22 & 59 & 65 & 97 & 109 & 525 \\
\hline Morgan, Gareth & 6 & 3 & 4 & 5 & 3 & 1 & 6 & 5 & 20 & 22 & 75 \\
\hline Schein, Edgar & 6 & 2 & 1 & 2 & 2 & 3 & 9 & 10 & 4 & 8 & 47 \\
\hline We ber, Max & 4 & 4 & 6 & 4 & 3 & 2 & 1 & 6 & 9 & 5 & 44 \\
\hline Mintzbe rg, Henry & 1 & 3 & 6 & - & 4 & - & 9 & 2 & 11 & 5 & 41 \\
\hline Hofs tede, Gee rt & 1 & 1 & - & - & 2 & 2 & 5 & 5 & 3 & 7 & 26 \\
\hline Pettigrew, Andrew & - & 4 & - & 1 & 1 & - & 5 & 8 & 3 & 4 & 26 \\
\hline B urrell, Gibson & 2 & 1 & 1 & 1 & 1 & 1 & 1 & 1 & 6 & 8 & 23 \\
\hline Senge, Peter & - & - & - & - & - & 2 & 4 & 2 & 2 & 8 & 18 \\
\hline Child, John & 2 & 1 & 1 & - & 2 & 2 & 1 & 2 & 4 & 3 & 18 \\
\hline DiMaggio, Paul & 1 & 1 & 1 & 1 & 2 & 1 & 1 & 2 & 3 & 5 & 18 \\
\hline Williamson, Oliver & 4 & 5 & - & - & - & - & 1 & - & 3 & 3 & 16 \\
\hline Argy ris, Chris & 2 & - & - & - & - & - & 6 & 3 & 2 & 1 & 14 \\
\hline Taylor, Frede rick & 2 & - & 1 & 2 & 1 & 2 & 2 & - & 3 & 1 & 14 \\
\hline B rave rman, Harry & 1 & 2 & - & 2 & - & 1 & 1 & 1 & 2 & 3 & 13 \\
\hline Crozier, Michel & 3 & 1 & 1 & - & - & 1 & - & 3 & 2 & 2 & 13 \\
\hline We ick, Karl & 1 & - & 1 & - & 1 & 1 & - & 1 & 3 & 4 & 12 \\
\hline Simon, Herbe rt & 1 & - & - & - & - & - & - & 1 & 8 & 2 & 12 \\
\hline Lawrence, Paul & 1 & 1 & - & 1 & - & 2 & 1 & 1 & - & 2 & 9 \\
\hline Fayol, Henri & 3 & - & 1 & - & - & 1 & - & 1 & 2 & - & 8 \\
\hline March, James & 1 & 1 & 3 & - & 1 & - & - & - & 1 & 1 & 8 \\
\hline Chandler, Alfred & 3 & 3 & - & - & - & - & - & 1 & - & - & 7 \\
\hline Hannan, Michael & 1 & - & 1 & - & 3 & - & 1 & - & - & 1 & 7 \\
\hline He zberg, Frede rick & 2 & - & - & 2 & - & 1 & - & - & - & 1 & 6 \\
\hline Pfe ffe r, Je ffre y & 2 & - & - & - & - & - & - & 2 & 2 & - & 6 \\
\hline Handy, Charles & 1 & - & - & - & - & - & - & 2 & 1 & 1 & 5 \\
\hline Burns, Tom & 2 & 1 & - & - & - & - & 1 & - & - & 1 & 5 \\
\hline Bartle tt, Christopher & 1 & - & - & - & 2 & - & - & - & - & 1 & 4 \\
\hline Hickson, David & - & 2 & - & - & - & - & 1 & 1 & - & - & 4 \\
\hline \begin{tabular}{|l|} 
Peters, Thomas \\
\end{tabular} & 1 & - & - & - & - & - & - & - & 2 & 1 & 4 \\
\hline Fre eman, John & & & & & & & & - & 1 & 2 & 3 \\
\hline Kanter, Rosabeth & & & & & & & & 1 & 1 & 1 & 3 \\
\hline Trist, Eric & - & - & - & - & - & - & 3 & - & - & - & 3 \\
\hline Waterman, Robert & 1 & - & - & - & - & - & 1 & - & 1 & - & 3 \\
\hline Mile s, Raymond & & & & & & & & 1 & - & 2 & 3 \\
\hline Pugh, De rek & 1 & 2 & - & - & - & - & - & 1 & 1 & - & 2 \\
\hline Salancik, Ge rald & - & - & 1 & - & - & - & - & 1 & - & - & 2 \\
\hline Snow, Charles & & & & & & & & 1 & - & 1 & 2 \\
\hline Lorsh, Jay & - & - & - & - & - & - & - & - & - & 1 & 1 \\
\hline
\end{tabular}




\section{Acesso à Estrutura Social da Disciplina como uma Instituição INTERNACIONAL}

Devido ao tamanho de sua economia, por apresentar amplo e diversificado setor privado, o Brasil é um país com um considerável potencial para o desenvolvimento de uma teoria administrativa independente. É um dos maiores receptores de capital estrangeiro e no ano passado foi o maior depositário de investimento norte-americano no mundo. Tem um sistema educacional bem desenvolvido e distribuído de pós-graduação em administração em funcionamento há mais de vinte anos. Considerando os tópicos preferidos no Brasil, pode-se observar que há muita influência do mundo anglo-saxônico e até trabalhos em conjunto, mas não muitos; porém já é notória a pouca expressão dos trabalhos brasileiros nos periódicos internacionais.

Algumas razões podem explicar esse quadro, como a dificuldade em se definir a identidade dos estudos organizacionais no Brasil. Não se pode afirmar que a fragmentação é mais evidente no Brasil, mas certamente não se observa a replicação de estudos já feitos, nem o uso de modelos já experimentados por outros autores, o que dificulta a criação de linhas paradigmáticas e tradição na área. Pode-se também levantar algumas razões pelas quais o conhecimento gerado no Brasil não é tão referenciado na sua própria terra: o alcance dos trabalhos é limitado em termos internacionais, há certa dificuldade de reconhecimento do trabalho um do outro e pelos próprios discípulos, o que torna a citação como instrumento de criação de tradição teórica pouco efetiva. Assim a literatura estrangeira ganha espaço como elemento formador de consenso e tradição na área, permanecendo a área contraditoriamente dividida entre os que acreditam que os modelos estrangeiros não têm nenhuma utilidade para o contexto brasileiro, e os que se apóiam inteiramente na literatura estrangeira e acreditam que muitas das inovações não têm sido produzidas internamente. Esse tipo de separação reflete uma ausência de lideranças no próprio cenário nacional e evidencia certa fragilidade do sistema, cuja base hierárquica se assenta no prestígio acadêmico.

$\mathrm{Na}$ verdade, se afirmarmos que a academia enquanto instituição é fraca, uma das explicações para isto deve-se a falta de suporte de um sistema de citações de certa densidade, o que por sua vez depende do grau de institucionalização das atividades acadêmicas. Por exemplo, uma determinada universidade pode sinalizar a importância dessas atividades por meio do investimento em recursos e decisões que possam fortalecer a pesquisa. No Brasil a obtenção de uma reputação positiva nas universidades públicas não está coerentemente ligada às publicações acadêmicas, nem existe um sistema de carreira no qual as publicações, nos principais periódicos, signifique reconhecimento social e intelectual, acesso a recursos e fórum de decisão. Nenhuma das universidades públicas - mesmo as 
consideradas mais acadêmicas entre as instituições de ensino superior no Brasil reconhece o tempo gasto com publicações como horas legítimas de trabalho. $\mathrm{O}$ trabalho é somente considerado como tal se ele for visível e tiver resultados imediatos, como acontece no ensino. A maneira como se vê o trabalho acadêmico no Brasil e, neste caso, estamos referindo-nos ao trabalho acadêmico em estrito senso, não implica uma visão contraditória, pois ela combina com a cultura brasileira, a qual favorece mais a comunicação informal e verbal do que a formal e escrita (Rodrigues, 1996).

Embora tenha sido possível identificar interesses comuns em termos do que é discutido nos estudos organizacionais no Brasil e no contexto internacional, parece haver uma diferença fundamental na maneira em que os temas são abordados. Aparentemente os autores brasileiros não se sentem obrigados a referir-se a trabalhos prévios na forma em que é exigido por periódicos americanos e britânicos. Conforme Astley (1985) assinalou, para serem publicados em periódicos de renome, os artigos têm de apresentar um equilíbrio entre a tradição e a inovação; entretanto a construção teórica ou os modelos conceituais como base de discussão das questões organizacionais não são elementos tão valorizados nos critérios de publicação. A investigação de artigos publicados no país não revela uma detalhada revisão literária, conforme encontramos em renomados periódicos americanos e britânicos. Em parte, por haver uma opinião formada de que é suficiente referir-se aos trabalhos pioneiros da área, ou àqueles centralmente posicionados no sistema hierárquico reputacional (Üsdiken e Pasadeos, 1995). Isso ocorre por razões práticas, como, por exemplo, devido às deficiências existentes na coleção de periódicos internacionais reunida em nossas bibliotecas, o que tem levado autores brasileiros, tradicionalmente, a confiarem na literatura clássica ou no trabalho pioneiro.

As diferenças com relação à sofisticação teórica são, portanto, fatores importantes que distinguem as publicações nos periódicos de reputação no Brasil e nos países anglo-saxões. Nestes países a comprovação do conhecimento se dá tanto pela sofisticação teórica quanto pela sofisticação empírica; enquanto no Brasil em vez de a teoria ser elaborada com base em vários trabalhos já feitos em determinado tema é, de fato, extraída de apenas um ou dois autores com mais tradição na área. Assim, a função principal da teoria passa a ser a de ilustrar um ponto da realidade, mais do que servir como ponto de partida para construção de determinado argumento; portanto é rara a prática de contestação sistemática, ou seja, aquela fundamentada em argumentos opostos. A idéia de que autores "devem constantemente defender suas idéias contra advogados de perspectivas alternativas" (Astley, 1985, p. 505) e desta forma contribuir para a acumulação de conhecimentos e idéias ainda não constitui prática efetiva no Brasil. Pelo contrário, é comum surgir inesperadamente uma nova idéia sem preocupações de se 
mencionar com rigor o que já foi feito sobre determinado assunto. Desta forma, as idéias vêm e vão mais facilmente, sem que haja consolidação e consenso em torno de modelos ou teorias e, portanto, sem construir tradição. Em outras palavras, a fragmentação que aparece no Brasil reflete a pouca preocupação com a consolidação de conhecimento. Essa situação pode ser explicada pela nossa carência no aprofundamento dos conhecimentos sobre os paradigmas dominantes na ciência (Üsdiken e Pasadeos, 1995) e ausência de uma rede de cooperação bem estruturada para apoiar um dado conjunto de idéias. Desse modo, é pouco provável que aqui o sistema viesse a brigar para preservar certo nível de consenso e a integridade ou a reputação de teorias, como acontece nas regiões mencionadas acima. Nem há por parte da academia brasileira de administração uma estrutura social, firme o suficiente, capaz de assegurar idéias, mesmo as originárias em alguma outra parte do mundo, por um prazo mais longo.

Na investigação realizada sobre artigos publicados nos anais do ENANPAD, considerado o fórum mais importante para a discussão dos estudos organizacionais, tanto a maioria dos estudos de casos quanto os estudos quantitativos focalizavam os problemas práticos. Os artigos dispostos nos quatro principais periódicos mostraram uma relação mais próxima com o mundo concreto, refletindo as contradições de uma visão de mundo que tenta valer-se de interpretações internacionais para explicar razões que são, na essência, locais. As ligações mais próximas do mundo concreto da gerência podem ser vistas ou como virtude, ou como vício. Em qualquer caso, o que deve ser confrontado é o fato de que, em um mundo onde a competitividade é a principal força motriz (Porter, 1986; Kogut, 1993; Pfeffer, 1994), torna-se crítico chegar a soluções práticas; entretanto uma excessiva ênfase na práxis pode colocar uma ameaça na posição desfrutada pela academia na definição do que se considera como qualificação gerencial de alto nível (Porter e Mckibben, 1988; Mowday, 1997). Nos Estados Unidos, as universidades corporativas estão se tornando as maiores protagonistas da educação continuada. Na Europa, mesmo as universidades mais tradicionais, têm procurado responder às pressões ambientais mediante o lançamento de MBAs mais curtos, ou Internet (vide os anúncios da Economist $7^{\text {th }}-13$ de junho de 1997). No Brasil, muitas instituições que não pertencem ao sistema de educação superior tradicional começaram recentemente a oferecer MBAs. Para um país como o nosso, no qual a institucionalização dos valores acadêmicos é ainda frágil, tais mudanças podem representar uma ameaça séria às instituições mais acadêmicas, tornado-as ainda mais vulneráveis à pressão do mercado. 


\section{REFERÊNCIAS BibLIOGRÁFICAS}

ASTLEY, G. W.

Administrative science as socially constructed truth. Administrative Science Quarterly, v. 30, p. 497$513,1985$.

BENSON, K. J.

Organizations: a dialectical view. Administrative Science Quarterly, v. 22, p. 1-21, 1977.

BERTERO, C. O.;

KEINERT, T. M. M.

A evolução da produção brasileira em análise organizacional a partir dos artigos publicados pela RAE no período de 1961-93. Revista de Administração de Empresas, v. 34, p. 81-90, 1994.

CALÁS, M. B.

Voicing seduction to silence leadership. Organization, v. 1, p. 243-248, 1994.

CHANLAT, J. F.

Francophone organizational analysis (1950-1990): an overview. Organization Studies, v. 15, p. 47-79, 1994.

CLEGG, S. R.;

HARDY, C.

Introduction organizations, organization and organizing. In: CLEGG, S. R.; HARDY, C.; NORD, W. R. (Eds.). Handbook of organization studies. London: Sage Publications, 1996. p. 1-29.

CLEGG, S. R.;

HARDY, C.;

NORD, W. R. (Eds.).

Handbook of organization studies. London: Sage Publications, 1996.

GÜILLÉN, M.

Models of management. London: The University of Chicago Press, 1994.

HOFSTEDE, G.

Culture's consequences: international differences in work-related values. London: Sage Publications, 1980.

Cultures and organizations. London: Harper Collins, 1994.

KOGUT, B.

Country competitiveness. Oxford: Oxford University Press, 1993. 
MACHADO-DA-SILVA, C. L.;

CUNHA, V. C.;

AMBONI, N.

Organizações: o estado da arte da produção acadêmica no Brasil. In: XIV ENCONTRO ANUAL DA ANPAD (1990: Florianópolis). Anais... Florianópolis: ANPAD, 1990. v. 6. p. 11-28.

MOWDAY, R. T.

Presidential address: reaffirming our scholarly values. The Academy of Management Review, v. 22, p. 335-345, 1997.

PFEFFER, J.

Competitive advantage through people. Boston, MA: Harvard Business School Press, 1994.

PORTER, M. E.

Competition in global industries. Boston, MA: Harvard Business School Press, 1986.

PORTER, L. W.;

MCKIBBEN, L. E.

Management education and development: drift or thrust into the 21 st century. New York: McGraw-Hill, 1988.

PUGH, D. S.;

HICKSON, D. J.

Writers on organizations. London: Sage Publications, 1997.
REED, $\mathrm{M}$.

Organizational theorizing : a historically contested terrain. In: CLEGG, S. R.; HARDY, C.; NORD, W. R. (Eds.). Handbook of organization studies. London: Sage Publications, 1996. p. 31-57.

REED, M.;

HUGHES, M.

Rethinking organization. London: Sage Publications, 1992.

RODRIGUES, S. B.

Management in Brazil. In: WARNER, M.(Ed.). International encyclopedia of business and management. London: Routledge, 1996. v. 3. p. 2673-2682.

ÜSDIKEN, B.;

PASADEOS, Y.

Organizational analysis in North America and Europe: a comparison of co-citation networks. Organization Studies, v. 16, p. 503-526, 1995.

VERGARA, S. C.;

CARVALHO, D. D. S.

Nacionalidade dos autores referenciados na literatura brasileira sobre organizações. Revista Brasileira de Administração Contemporânea, v. 1, n. 6, p. 170-188, 1995. 
WHITLEY, R.

Academic knowledge and work jurisdiction in management. Organization Studies, v. 16, p. 81-106, 1995.
WILSON, F.

Research note - organizational theory: blind and deaf gender? Organization Studies, v. 17, p. 825-842, 1996. 